£3 0 s. 4 d. at the Leeds General Infirmary. The special hospitals show equally startling discrepancies. Out of a total of 4579 buds for the whole metropolis, 3486 are provided by the hospitals situated within a radius of a mile and a half from Charing Cross. At present North London, with a population of nearly $1,000,000$, possesses but one hospital, the Great Northern, with 33 beds; the East-end, with its river-side and manufacturing population of $1,100,000$, is dependent upon the London Hospital with 790 beds, and the Metropolitan Free Hospital with 20 beds, both of which are inconveniently situated for a large proportion of the inhabitants. The West-end, with a population of 950,000 , has but two hospitals-St. Mary's with 190, and the West London with 60 beds respectively. A population of nearly one and a half millions on the Surrey side of the Thames has to rely upon Guy's with 700 beds and St. Thomas's with 400 available beds. The unsatisfactory condition of the present out-patient system, and especially of that in force at the large metropolitan hospitals, demands reform. At the present time more than a million people, or one in three, receive relief at the London hospitals. It is desirable that every hospital and medical institution intended for the relief of the suffering poor should be ad. ministered by a board of management, subject to periodical election by the governors, upon which board the medical staff of the charity should be adequately represented. An authoritative supervision over the administration and a public audit of the accounts of all such institutions are needed to secure a right distribution of medical relief, and a more econcmical expenditure of the funds entrusted to the boards of management. A public audit is a bsolutely necessary to check extravagance and to protect the public, which has at present but little or no voice in restraining reckless mismanagement. An authoritative supervision would prevent foolish squandering, the occupation of unhealthy and unsuitable buildings as hospitals, and would promote good feeling between the hospital authorities and the medical staff. The absence of organisation and combination amongst the medical institutions throughout the country materially lessens their usefulness. This is strongly enforced by the enormous and needless difference in the cost of management and maintenance of different hospitals. In the administration of the wards, so far as it affects the treatment of the patients, and especially in the management of the nursing arrangements, the medical staff should have an authoritative voice. Recent events have shown the public and the medical profession to be in substantial accord on this point. Unfortunately, in the majority of the large hospitals the nursing arrangements are under the control of a matron, aided by a nursing committee, and only indirectly, if at all, assisted by those alone qualified to direct-viz., the medical staff. Out of twenty-two hospitals having medical schools, there are but seven where this important depaltment is superiniended by a nursing committee upon which the medical element is represented. The importance of medical education, and the adequate training of the members of the medical profession, require an intelligent recognition of the relation of the hospitals to their medical schouls, to eusure an improvement in such relations. Medical education in this country, however, almost entirely depends upon private speculation and haphazard enterprises whose success rests upon the preservation of a harmonious relationship between corporations with apparently separate aims. Should this harmony between hospital and school at any time be ruptured, the existence of the school becomes at once imperilled, thereby seriously endangering the interests of the public. During recent years the Metropolitan Asylums Board has built and opened some of the most extensive and complete of modern hospitals. These infirmaries afford a magnificent field for the treatment and investigation of disease, fur pathological research, and for medical education. The appointment of a controlling authoity, endowed with adequate powers to sanction, restrict, or prohibit the erection of a new or the extension of an already existing hospital or dispensary, was, he thought, urgently called for. The social and public aspects of the question of the right of government of our hospitals alone demand an immediate investigation, since it is not the sick poor at all are being benefited, but nearly the whole wage-receiving and industrial classes, a large proportion of whom are well-paid artisans.

Mr. Michael, Q.C., read a paper advocating the Compulory Notification of Infectious Diseases, and said that the system had been adopted in some towns under private Acts; but he desired to see the principle generally applied.

\section{THE SERVICES}

Army Medical Department.-Brigade-Surgeon Henry Joseph Rose is granted retired pay, with the houorary rank of Deputy Surgeon-General; Surgeon-Major Richard Colville Parkinson has been placed on temporary half-pay; the second Christian name of Surgeon Johnston, M. B., is Halcro, and not Halero, as stated in the Gazette of August 23rd, 1881 ; the surname of the surgeon described in the Gazette of August 23rd, 1881, as William Baptie, M. B., is Babtie.

Madras Medical Establishment. - Surgenn-Majors to be Brigade-Surgenns, dated 27th November, $1879:-$ Joveph Marcus Josepb, M. D. ; Edward Somerset Cleveland, M.D. ; William Henry Hiarris, M. D. (since retired); William Henry Rean, M.D. ; Alfied Sanderson, M.D. ; Clarence Cooper, M.D.; Samuel Jardine Wyndowe, M.D. (since retired) William Robert Curnish, C.I.E. ; Ardern Hulme Beaman George Stewart Watson Ogg; William Pearl; Edmund Eyre Lloyd, dated 1st April, 1880 ; Michael Cudmore Furnell, M.D., dated 16th May, 1880 ; George Alexander Burn M.D., dated 7 th February, 1881 ; Hobert Dempster, dated 28th March, 1881

Militia MEdical Department. - Surgeon - Major Thomas Starkey Smith, 3rd Battalion, the Prince of Wales's Volunteers (South Lancashire Regiment), resigns his com. mission, dated 5th Oetober, 1881.

ADMIRALTY.-The following promotion has been specially made for gallant conduct at the action of Majuba Mountain, during the recent operations in the Transvaal :-Surgeon Edward Elphinstone Mahon to be Staff-Surgeon in Her Majesty's Fleet, with seniority of July 18th, 1881. The following promotions have been made :-Staff. Surgeon James Trimble to be Fleet-Surgeon in Her Majesty's Fleet, with seniority of 20th ult. ; Staff-Surgeon John T. Comerford, M.D., Pembroke, additional for Melville Hospita!, vice Trimble; Staff-Surgeon Robert Turner to the Hibernia, in lieu of a surgeon, vice Comerford; Staff-Surgeon Robert Grant, M.B., to the Duke of Wellington, in lieu of a surgeon, vice Turner; Staff-Surgeon James Dunlop to the Espiegle; Surgeon Francis R. M. Loftie to the Flora, additional, vice Mahon.

\section{Utorespondente.}

"Audi alteram partem."

\section{THE TREATMENT OF THE INSANE IN PRIVATE DWELLINGS.}

\section{To the Editor of THE LANCET.}

SIR,-As no one has called attention to the abuse of statistics, on which depends a portion of the position you take up in THe LANCET of Sept. 3rd in regard to the treatment of the insane, I desire to submit a few facts.

The insanity with which Prichard, Willis, Burrows, \&c., dealt when they secured the large proportion of recoveries you adduoe consisted of acute mania and melancholia; and it shows either reprehensible ignorance or something worse than a want of candour for a writer in THE LANCET to suggest a comparison of these statistics with those of the whole admissions of modern asylums. The admissions of asylums now include a large percentage $(40,50,60$ per cent., in this asylum last year 66 per cent.) of cases of idiocy, epilepsy, senile dementia, general paralysis, and other coarse brain diseases usually in an advanced stage, and of those cases that have become chronic, often by failure to recover under treatment in private dwellings.

If you will refer to some statistics which I presented in the Journal of Mental Science for July, 1877, you will see that there is every reason to believe that of the class of cases on which the dogma of the great curability of insanity is founded, county asylums now cure 84 per cent, a figure which contrasts favourably with the older statistics, when it is remembered that the latter included also the slighter and more transient cases which are successfully treated at home and not sent to asylums, and also included recurrent cases, by aid of which some almost miraculous statisties of the cure of insanity have ere now been given ( 100 per cent. and upwards). A perusal of earlier papers on this subject would also show you that this great curability, even in selected cases, either in the olden time or now, is more apparent than 
real, and is founded largely on cure of attacks or cases, not of persons.

1 know little of private asylums, and speak only from the public asylum point of view; and though $I$ disagree with you when you show an ignorance of statistics which is discreditable to a leading journal like THE LANCET, and still more when you indulge in what is little better than indiscriminate and unfounded abuse of the specialty to which I belong, I do agree with you in asserting that, under the gradual development of the desire to have the insane poor properly cared for, whilst no other method of doing so than sending them to the asylum is available, and under the stimulus of a divided chargeability, masking the costliness of the process, an immense mass of broken-down humanity is now sent into county asylums-a mass of which a large proportion might more suitably be cared for in private dwellings : and of whom, I may add, a large proportion would not have been regarded as "insane" in the good old times to which your couleur de rose statistics refer.

The present impediment to their now being cared for in private dwellings is that a sufficient pecuniary allowance is rarely or never granted by the Poor-law guardians, who have to deal with such cases on routine pauper principles, and that there is no adequate supervision available to ensure their proper care, and that such allowance is expended for their benefit. I believe these difficulties are only to be overcome by entirely removing the care of lunacy from the ordinary Poor-law authority, and placing all lunacy under a special county authority, subject to a separate central Government department.-I am, Sir, yours, \&c.,

$$
\text { T. A. CHAPMAN, M.D. }
$$

Hereford County and City Asylum, Sept. 27th, 1881.

** It is passing strange that correspondents cannot dis cuss this question without a vehemence which seems to indicate loss of temper. It is possible to be plain and forcible without being abusive. For rejoinder to the remarks offered on our use of statistics, and the "reprehensible ignorance, or something worse than want of candour," shown by "a writer in THE LANCET" (or, in more correct phraseology, ourselves), we will only reply that the comparison we institute is not based on the returns published by the Commissioners, but on a calculation of returns made by medical officers of asylums in which an opinion is expressed as to the nature of the cases under their care. These returns are counter-checked on the evidence supplied by the average period of residence in asylums in the several classes of cases discharged as cured. We can assure our correspondent that we do not ignore the fact that the bulk of the asylum population is now, whatever it may have been in the past, incurable. Insanity is very apt to become "incurable" when it is simply diagnosed and classified as incurable, and left to, let us say, nature.-ED. L.

\section{THE INTERNATIONAL MEDICAL CONGRESS. To the Editor of THE LANCET.}

SIR,-I regret to find that the report given in THE LANCET of Aug. 13th, p. 297, of my remarks on Professor His's communication to the Anatomy Section of the International Medical Congress and the accompanying statement of the general opinion of the meeting are such as to convey a somewhat erroneous impression of what passed, and to express more of dissent from Professor His's proposition than was intended by the speakers on that occasion.

Without entering into the details of the discussion, which will find their proper place in the forthcoming report of the proceedings of the Congress, I am desirous, through your journal, to explain that the object of my remarks was to say, that from Professor His's interesting statement of facts and illustrations brought before the meeting, and from the valuable contributions to the knowledge of human embryology contained in his recently published work on that sub. ject, I could then more readily than formerly give a general assent to his proposition-viz., "That the number of human embryos observed was now such as to enable us to determine their normal characters;" but that at the same time I still had some fear that in the earliest stages of development the pathological conditions so frequently existing in aborted products greatly interfered, and perhaps more than Professor
His might be disposed to admit, with the determination of some doubtful points of structure; and that in particular further observations would be required to establish with certainty the mode of origin and early condition of the allantois which he had described.

I did not, however, mean by this to assert that Professor His had not taken due care to guard against error from the existence of the pathological conditions referred to, which conditions he nust know as fully as most other embryologists; nor do I think that the anatomists present at the meetivg went further than I did in expressing doubts as to the validity of the evilence adduced by Professor His in support of his proposition. On the contrary, I should say that they fully appreciated, as I did, the scrupulous care in observation aud the extensive and accurate knowledge of his subject, which gave a high value to Professor His's communication.-I am, Sir, your obedient servant,

London, Oct. 1st, 1881. ALLEN THOMSON.

\section{Mllotical adtetos.}

UNIVERSTT OF EDINBURGH. - The following is the list of candidates who received the Degrees of Doctor of Medicine, Bachelor of Medicine, and Master in Surgery, on Aug. 1:Docror OF MEDICINE.

Adam, John (M.A. Elin.), Scotland, M.B. and C.M.

Alexander, Reginald Gervase (M.A. Cantab.), England, M.B. and C.M Clarke, Henry Joy, England, M. B. and C MI.

tCloustun, Chas. S. Orkney, M.B. and C.M. (Second Class Honours).

Collie, David, Scotland, M. B. and C.M.

†Coldstream, Alexander Robert, scotland, M.B. and C.M.

Cox, Joshua John, Treland, M..E.

tDavison, James Thomas Richard, Argentine Republic, M. B. and C.M. tDeverell, Henry George, Indla, M.B. and C.M.

†Douglas, Charles Edward, India, M.B. and C.M.

tGibson, George Alexander (D.Sc. Edin.), Scotland, M.B. and C.Mr.

*Hay, Matthew, Scotland, M.B. and C.MI. (with First Class Honours and Ettles Prizeman)

†Lamb, William, Scotland, M B. and C.M.

$\dagger$ Lawson, Robert, scotland, M.B. and C.M

Low, Alexander Bruce, Scotland, M.B. and C.Mr.

M'Bride, Peter, Hamburg, M.B. and C.MI.

Macnaughton, William Alex. (M.A. Edin.), Scotland, M.B. and C.M.

+M'Donald, Duncan (B. Sc. Edin.), Scotland, M.B. and C.M.

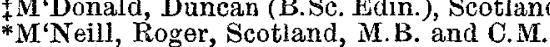

tMiller, Willam Birkmyre (M.A. St. And.), Scotland, M.B. and C.M.

*Moodie, Robert, Scotland, M. B. and C. .I.

tMurray, James (M.A. Edin ), Scotland, M.B. and C.M.

tOram, Arthur MLurray, Australia, M. B. and C.M.

Oswald, Henry Robert, India, M. B. and C.M.

Pountney, William Edward, England, M.B. and C.M

tShaw, Oliver Cromwell, England, M.B. and C.M

†Sanctuary, Thomas, England, M.B.

Smith, Andrew, Scotland, M.B. (with Second Class Honours).

†Thomson, David George, Scotland, M.B. and C.M.

tTrotter, Leslie Batten, England, MI B. and C.M.

Turner, William (M.A. Aberd.), Scotland, M.B. and C.M.

Williams, William Henry, England, M.B. and C.M

Williamson, Robert Lamley, England, M. B. and C.M.

Wilson, John, Scotland, M.B. and C.M.

*Woodhead, German sims, Eugland, M.B. and C.M.

* Those who have obtained Prizes for their Dissertations.

$\dagger$ Deemed worthy of competing for the Dissertation Prizes.

Commended for their Dissertations.

Bachelor of Medicine and Master in Surgery. Aitken, James Hepburn, Scotland. Baildon, Francis Joseph, England. Balfour, John Hutton, Scotland. Bannerman, William Burney, Scotland.

$\S$ Baron, Barclay, Josiah, Fngland.

Bateson, John Francis, England.

Bennett, Richard Charles, Trinidad.

Birrell, Wm. Geo., Scotland. (Received the Degrees on 'Nov. 27 th, 1880 .)

Black, John Lyell, Scotland.

Blaikie, Rubert Henry, Scotiand.

Borthwick, Thomas, scotland.

¿Bowes, Robert, Scotland.

Bradley, William Edward, England.

Brodie, William Haig, Scotland.

Brown, Thomas, Scotlan.

Bruce, David, Australia.

, Received the Degrees on Nov. 27 th, 1880.)

Buchan, John Greig, Orkney.

Calder, James Arthur Lawrence, Jamaica.

Clark, Henry Martyn, India

Corser, Francis Richard Sandford, England.

Cox, James Wharton, Sydney.

Dalzell, William Robert (M A. Edin.), India.

Delepine, Camille Victor, France.

Doig, William, Scotland.

Douie, William Jones, Scotland.

Doyle, Arthur Conan, Scotland.

Dunlop, James Dunlop, Scotiand.

Fearns, Robert, Scotlund.

Ferguson, James Mitchell, Scotland. 